\title{
Comprehensive Evaluation of Metro Project Bidding Risk Based on Entropy Value Method and Fuzzy
}

\author{
J.X. ZHAO, M. LIU, L. LI \\ Qingdao Technological University, Qingdao, China
}

\begin{abstract}
This paper proposes risk evaluation system of metro project bidding based on factors which the environment and process of metro project bidding involved. Then the paper uses the entropy value method to determine the weights of the index and adopts Fuzzy to evaluate risk management level of metro project bidding, which takes the vagueness and uncertainty into account with a combination of both methods. According to the evaluation results, the paper puts forward recommendations for improvement and verifies the feasibility of the evaluation model.
\end{abstract}

KEYWORD: Bidding of Metro Project; Risk Management; Entropy Value Method; Fuzzy

\section{INTRODUCTION}

With urbanization gradually accelerate, the urban population urban expands rapidly and public transport becomes congested increasingly. It promotes the development and construction of the metro. Recently, metro not only has become an important public transportation, but also become an important indicator of economic strength, living standards and comprehensive competitiveness in a country or city modernization. Due to the risks in metro project bidding process, the danger of metro construction will be further enlarged and superimposed, even cause safety accidents in metro project. Therefore, metro project bidding is the foundation of the entire metro construction project on risk management. It is necessary to conduct a comprehensive analysis on risk management of metro project bidding.

There are many scholars have done in-depth research for risk management of metro projects in different stages, the main researchs are as follows. The first categorie is the research of bidding risk.C.G.Lu and B.Hou conduct risk management of metro project bidding from the perspective of owners (Lu,2010; Hou,2010). The second categorie is the research of exploration risk.P.X.Ma analazes the factors of geological risk in metro construction (Ma etal.,2009). The third categorie is the study on design risk.Z.X.Feng proposes the methods, practices and procedures of control system design risk (Feng,2012). The fourth category is the discuss of construction risk.L.Y.Ding and J.J.Zhou conduct the evaluation studies on metro construction risk (Ding etal., 2012; Zhou etal.,2009).The fifth class is the study on operational risk. H.W.Huang discusses the characteristics and definitions of metro operational risk management (Huang etal.,2008).

In this paper, object of study is risk management of metro project bidding. Firstly, the paper builds evaluation index system from the aspects of tenderee behavior, bidder behavior and bidding environment. Secondly, the paper uses the entropy value method to determine the weights of the index and introduces Fuzzy to evaluate risk management level of metro project bidding. Finally, suggestions for improvement are proposed in line with the evaluation results.

\section{OUTLINE OF THE METHODS}

\subsection{The entropy value method}

The entropy value method is an objective weighting method, which attribute weights is completely unknown and property values are given in the form of interval numbers (Li etal.,2014). According to the degree of variation of each index, it uses information entropy to calculate entropy of each index. Then weights of each index are calculated by revising the entropy so as to arrive more objective index weight.

\subsection{Fuzzy}

Fuzzy is an evaluation method which applies the principles of fuzzy relations synthesis (Tong,2011). 
It conducts expert evaluation to index by using fuzzy matrix, then quantifis the results of the final evaluation through composite operations. It evaluates membership grades of indicators with a number of factors taken into account.

\section{THE RISK EVALUATION SYSTEM OF METRO PROJECT BIDDING}

\subsection{Establishment of Index System}

According to fators exist in process of metro project bidding, the paper analyses all links that affect safety of metro project from aspects of behavior and environment of implementation. Evaluation index system is shown in figure 1 :

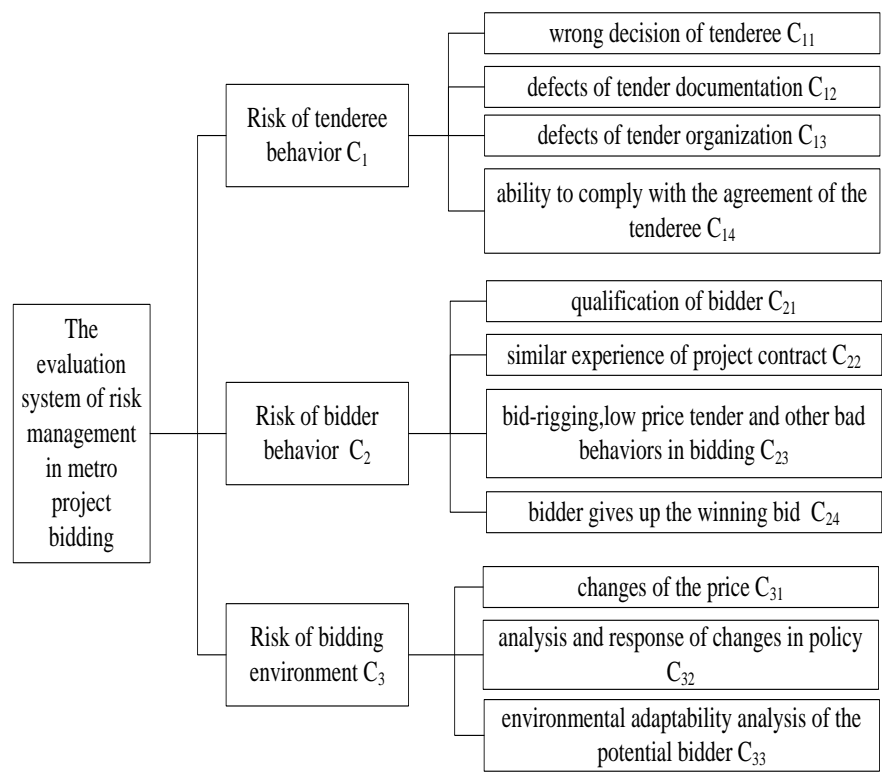

Figure1. The evaluation system of risk management in metro project bidding.

\subsection{Determination of Index Weights}

Use entropy method to determine the weight of each factor index in index system. The specific operation process is shown as follows:

(1) To calculate the importance of metro project bidding risk indicators in evaluation system decision-making data is obtained through research which construct the decision matrix $R=\left\{r_{i j}\right\}_{m \times n}$. Then the decision matrix must be standardized by $\dot{r}_{i j}=\frac{r_{i}}{\sum_{i n}^{m} r_{i j}}$. The normalized matrix is $\dot{R}=\left(\dot{i}_{i j}\right)_{m \times n}$.

(2) Calculate the information entropy of index, the specific calculation formula is(1)

$$
E_{i}=-\frac{1}{\ln n} \sum_{j=1}^{n} \dot{r}_{i j} \ln \dot{r}_{i j}, \quad i=1,2, \cdots, m
$$

(3) Calculate the weights of indicators, the specific formula is:

$$
\omega_{i}=\frac{1-E_{i}}{\sum_{k=1}^{n}\left(1-E_{k}\right)}
$$

Weight vector of indicators is $\omega=\left(\omega_{1}, \omega_{2}, \cdots, \omega_{n}\right)$.

According to the above steps, we can draw evaluation weights of metro project bidding risk indicators.

\section{RISK EVALUATION OF METRO PROJECT BIDDING BASED ON FUZZY}

In the foundation of evaluation index system of risk management of metro project bidding, we can evaluate the level of metro project bidding risk management. According to the fuzzy theory, the first step evaluation will be from program layer to criteria layer. The second step evaluation will be from criteria layer to target layer, which form the fuzzy synthetic evaluation model. Through this model, we can determine the true level of the risk management of metro project bidding. According to the specific metro project bidding, the specific evaluation step will be shown as follows:

(1) Establish Remark Set. It is presented by $V=\left\{V_{1}, V_{2}, V_{3}, V_{4}\right\}$, the remark set includes 4 grades: excellent, good, better, poor according to evaluation model. Every index corresponds to a actual grade, experts and relative staff should evaluate every index and give the corresponding grade.

(2)Establish Evaluation Matrix for Fuzzy Composition. $R_{i j}$ is the fuzzy evaluation matrix for judgment of all levels, the substance of which is a percentage. The grade percentage of every layers is obtained through the evaluation of relative experts and staff. In the matrix $i$ is the number of elements judged, $j$ represents the number of remark set grades. Fuzzy evaluation is realized by synthesizing the weight vector of all levels $W$ and evaluation matrix $\left(R_{i j}\right)$. The specific formula is $C_{i}=W_{i} \cdot R_{i j}$.

\section{SPECIFIC CASE}

Combined with process and environment of bidding used in Qingdao metro project, we invites eight experts and scholars specialised in the field of metro project bidding to provide decision-making data for metro project bidding risk evaluation system.

\subsection{Determination of Index Weights based on The Entropy Value Method}

Collect the decision-making data and quantitative the weighting matrix. Such as the index $C_{2}$. 
Table 1 Data of experts rate.

\begin{tabular}{|l|c|c|c|c|c|c|c|c|}
\hline index Expert & 1 & 2 & 3 & 4 & 5 & 6 & 7 & 8 \\
\hline$C_{21}$ & 85 & 85 & 80 & 75 & 85 & 80 & 80 & 75 \\
\hline$C_{22}$ & 80 & 80 & 75 & 80 & 75 & 85 & 80 & 75 \\
\hline$C_{23}$ & 70 & 80 & 85 & 75 & 75 & 80 & 80 & 70 \\
\hline$C_{24}$ & 75 & 85 & 80 & 75 & 80 & 85 & 75 & 80 \\
\hline
\end{tabular}

According to calculation steps of the entropy value method, we can get the weight of index $C_{2}$. The result is $\omega_{2}=\left(\begin{array}{llll}0.256 & 0.250 & 0.242 & 0.252\end{array}\right)$.

Similarly, the weight of index $C$ is $\omega_{0}=(0.3330 .3370 .330)$. The weight of index $C_{1}$ is $\omega_{1}=(0.2540 .2440 .2460 .256)$. The weight of index $C_{3}$ is $\omega_{3}=\left(\begin{array}{ll}0.336 & 0.3330 .331\end{array}\right)$.

\subsection{Evaluation of Bidding Risk}

The evaluation of each matrix are substantially in the same way, so we just need describe one matrix in detail without enumerating all of them. The result will be given in the form of a vector. Such as the fuzzy evaluation for $C_{1}$ :

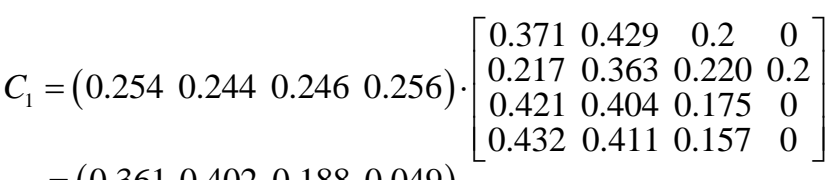

$$
\begin{aligned}
& =\left(\begin{array}{llll}
0.361 & 0.402 & 0.188 & 0.049
\end{array}\right)
\end{aligned}
$$

Similarly, we can get the evaluation results of other

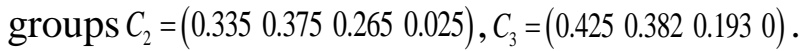

Finally, we can evaluate the level of metro project bidding risk management based on advice of experts. The fuzzy comprehensive evaluation for $C$ :

$$
\begin{aligned}
C & =\left(\begin{array}{lll}
0.333 & 0.337 & 0.330
\end{array}\right) \cdot\left[\begin{array}{llll}
0.333 & 0.400 & 0.267 & 0 \\
0.276 & 0.368 & 0.356 & 0 \\
0.371 & 0.327 & 0.202 & 0.1
\end{array}\right] \\
& =\left(\begin{array}{llll}
0.326 & 0.366 & 0.275 & 0.033
\end{array}\right)
\end{aligned}
$$

According to the maximum membership principle,

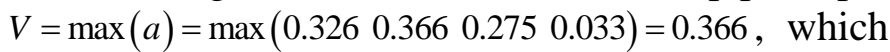
means that the evaluation result lays the biggest influence on $V_{2}$, which belongs to the remark set. Thus the risk management assessment of the metro project bidding shall be good.

It can be seen from the above results that the risk management level of index $C_{1}$ and $C_{2}$ is good, index $C_{3}$ is excellent. Therefore, we should first improve the management of tenderee behavior risk and bidders behavior risk in order to improve the risk management of metro project bidding ultimately.

\section{CONCLUSION}

According to the process and environment of metro project bidding, the paper establishs a risk evaluation system which mainly covers the risk of tenderee behavior, risk of bidder behavior and risk of bidding environment.

The entropy value method is used to provide the indicators with weights, which makes the weights more reasonable by calculating the entropy to determine the degree of impact on the comprehensive evaluation. Then with combination of qualitative and quantitative, we can evaluate the level of metro project bidding risk management based on fuzzy.

It can be conclude from calculation results that the risk management level of tenderee behavior and bidders behavior belongs to the "good" rating which need to be further improved. Supervisors should improve the surveillance of the risk in tenderee behavior and bidders behavior so as to improve the risk management of metro project bidding.

\section{REFERENCES}

[1] Lu,C.G. 2010.Research on proprietors' risk management in the metro project bidding. Hunan University.

[2] Hou,B. 2010.Study on urban rail transportation engineering project bidding risk management. North China Electric Power University.

[3] Ma,P.X. \& Guo.H.M. 2009. The geological risk factors and the corresponding measures in Beijing metro construction. West-china Exploration Engineering 1: 170-172.

[4] Feng,Z.X. 2012. Research on designing risk control system for urban rail transit project. Beijing Jiaotong University.

[5] Ding,L.Y. \& Zhou,C. 2012. Automatic identification and early warning of subway construction safety risks in complex environment. Engineering Sciences 14(12):84-93.

[6] Zhou,J.J. \& Song.Y.F. 2009. The study on subway construction risk based on WBS-RBS structure. Value Engineering 11:76-80.

[7] Li,L.\&Zhao,J.X.2014.Evaluation of metro project management effect based on entropy value method and gray theory. Journal of Qingdao Technological University 35(3):53-58.

[8] Tong,R.P. 2011.Common security evaluation method and its application. China Labor \& Social Security Publishing House. 